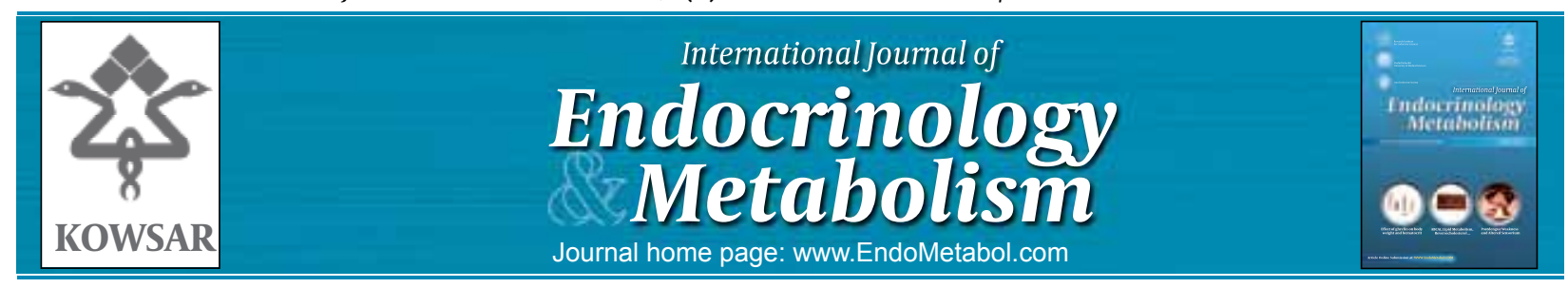

\title{
Effect of Clomiphene Citrate on Follicular Recruitment, Development, and Superovulation During the First Follicular Wave in Rahmani Ewes
}

\author{
Taymour Mohammed EL-sherry ${ }^{1^{*}}$, Derar Derar ${ }^{1}$, Hasan Ali Hussein ${ }^{1}$, Ahmed Yusef Shahin ${ }^{2}$, \\ Salem Fahmy ${ }^{3}$ \\ ${ }^{1}$ Department of Theriogenology, Faculty Vet Med, Assiut University, Assiut, Egypt \\ ${ }^{2}$ Department of Obstetrics and Gynecology, Women's Health Centre, Assiut University, Assiut, Egypt \\ ${ }^{3}$ Deparment of Animal production, Faculty of Agriculture, Al-Azhar University-Assiut Branch, Assiut, Egypt
}

\section{A R T I C L E I N F O}

Article type:

Original Article

Article history:

Received: 05 Feb 2011

Revised: 26 Apr 2011

Accepted: 07 May 2011

Keywords:

Clomiphene Citrate

Superovulation

Ewes

\begin{abstract}
A B S T R A C T
Background: Clomiphene citrate (CC) has been considered as the most effective drug to treat female infertility which is highly effective in inducing ovulation in females with anovulation or oligo-ovulation, however, it may induce partial inhibition of ovulation because of its inhibitory action on follicular growth and atresia of nonantral and mature follicles.

Objectives: The present experiment was conducted to study the effect of CC on follicular development (experiment 1) and superovulation (experiment 2) during the first follicular wave in Rahmani sheep with a 22-day ovulation cycle.

Patients and Methods: In experiment 1, the animals were divided into 2 groups, namely, control $(n=7)$ and CC $(n=6)$ groups. The estrous cycles of the animals in both groups were synchronized by administering two 15-mg/mL doses of Dinoprost at a 10-day interval. Onset of ovulation (day 0 [Do]) was confirmed by performing transrectal ultrasonography. The animals in the CC group received $100 \mathrm{mg}$ of oral CC daily for 5 consecutive days. In experiment 2, the estrous cycles of the animals were synchronized as mentioned previously, and the animals were divided into 2 groups: (1) the equine chorionic gonadotropin (eCG) group $(n=4)$, in which the animals received 2000 IU of eCG intramuscularly (i.m.) for 5 days, and (2) the eCG and CC group $(n=5)$, in which the animals received 2000 IU of eCG i.m and $100 \mathrm{mg}$ CC orally for 5 days. Results: We observed a significant $(P<0.05)$ increase in the number of follicles from D2 to D5 and in the levels of estradiol (E2) from D1 to D4 after CC treatment, with no significant differences between the progesterone (P4) levels in both the groups. The increase in the number of follicles in the eCG and CC group was not as significant as that in the eCG group. The E2 level in the eCG group was significantly higher than that in the eCG and CC group from D1 to D3. Conclusions: In conclusion, administration of CC increased the number of the growing follicles and plasma E2 levels. However, CC administered during superovulation did not increase the number of ovulating follicles and negatively affected the E2 level.
\end{abstract}

Copyright $\odot 2011$ Kowsar M. P. Co. All rights reserved.

Implication for health policy/practice/research/medical education:

The study is focusing on the effect of CC on the follicular development and superovulation in sheep. The result might be useful for researcher of animal and human reproduction, and reproductive endocrinology filed.

- Please cite this paper as:

EL-Sherry TM, Derar R, Hussein HA, Shahin, AY, Fahmy S. Effect of Clomiphene Citrate (CC) on Follicular Recruitment, Development, and Superovulation During the First Follicular Wave in Rahmani Ewes. Int JEdocrinol Metab. 2011;9(3): 403-8. DOI:10.5812/Kowsar.1726913X.2381

* Corresponding author: Taymour Mohammad EL-Sherry, Faculty of vet Med, Assiut University, Egypt. Tel:+20-882334699, Fax: +20-882366503, E-mail: timorsherry@yahoo.com

DOI:10.5812/Kowsar.1726913X.2381

Copyright $\odot 2011$ Kowsar M.P.Co. All rights reserved.

\section{Background}

For more than 4 decades, clomiphene citrate (CC) has been considered as the most effective drug to treat fe- 
male infertility (1). CC is a selective estrogen receptor modulator (SERM) $(2,3)$, which is highly effective in inducing ovulation in females with anovulation or oligoovulation. The structure of the drug is similar to that of estrogen but is distinguished by the presence of a substituted side chain (4). CC has an antiestrogenic effect on the hypothalamus (2). It blocks the estradiol-17 $\beta\left(E_{2}\right)-$ binding cytoplasmic or nuclear receptors, causing an increase in the levels of gonadotropin-releasing hormone (GnRH); this in turn causes an increase in the secretion of follicle stimulating hormone (FSH), which results in ovulation (1). CC maintains and even sustains normal follicular growth and development; however, it may induce partial inhibition of ovulation because of its inhibitory action on follicular growth and atresia of nonantral and mature follicles (5). Unlike in rodents, in rabbits, ovulation can be triggered by injection of human chorionic gonadotropin (hCG) after CC treatment (6). In ewes, CC acts as a weak ERM, which inhibits ovulation and induces estrous without ovulation (7). We concluded that CC treatment cannot elicit any pituitary-stimulatory or gonadotropin-like activities in sheep, and hence, cannot be applied in ewe breeding. However, in an experiment involving the use of CC to induce superovulation in ewes, only 3 out of 6 of the superovulating ewes exhibited estrous with a mean corpus luteum $(\mathrm{CL})$ numberof $2.3 \pm 0.3$ per animal (8). The data is contradictory on the clinical use of CC and its endocrinological effect in humans and animals, particularly ewes. The aim of this study was to evaluate the effect of CC on follicular development and hormonal changes during the first follicular wave (Experiment 1) and its effect on superovulation induced using pregnant mare serum gonadotropin (PMSG) (Experiment 2) in ewes.

\section{Materials and Methods}

\subsection{Animals and Experimental Design}

The ewes were housed indoors (with access to outdoor areas) at the experimental farm of Al-Azhar University, Assiut, Egypt (latitude $28^{\circ} 07^{\circ} \mathrm{N}$ and $30^{\circ} 33^{\circ} \mathrm{E}$ ). The ewes had free access to water and were fed a maintenance diet. The study was conducted during the breeding season of ewes at this latitude. Further, only cyclic ewes were selected for this study. Estrous cycles of the animals were synchronized by administering two $15-\mathrm{mg} / \mathrm{mL}$ doses of Dinoprost (Lutalyse, Pfizer, Belgium) at an interval of 10 days. For Experiment 1, the ewes were randomly divided into 2 groups: control $(n=7)$, in which the animals had a normal estrous cycle, and CC group $(n=6)$, in which the animals received $100 \mathrm{mg}$ of oral CC (Clomid, Global Napi Pharmaceuticals, Cairo, Egypt) daily for 5 consecutive days. For Experiment 2, the estrous cycles of the animals were synchronized as in the previous experiment, and the animals were divided into 2 groups: (1) the equine chorionic gonadotropin (eCG) group $(n=4)$, in which the animals received 2000 IU of eCG (Folligon, Intervet
International B.V., Holland, Netherlands) intramuscularly (i.m.) for 5 days, and (2) the eCG and CC group ( $n=$ 5), in which the animals received 2000 IU eCG and 100 mg of CC orally for 5 days. Follicular growth and development was monitored by ultrasonography, which was performed daily by the same operator until the end of the treatment duration. To measure the diameter of the follicle, we used an ultrasound scanner (Pie Medical, 100LC, Maastricht, The Netherlands ) equipped with a $6 / 8 \mathrm{MHz}$ linear transducer. The mean follicle diameter $(>2 \mathrm{~mm})$ through each set examinations was recorded. On the basis of the mean follicle diameter, the observed follicles were classified as small (diameter, $<3 \mathrm{~mm}$ ), medium (diameter, 3-5 mm), and large (diameter, $>5 \mathrm{~mm}$ ). All the recorded ultrasound images were printed.

\subsection{Blood Collection and Determination of Hormone Levels}

Blood sampling was performed from days 1 to 5 (D1-D5) immediately after each ultrasonography examination and at 24-h intervals by jugular venipuncture and 10-ml heparinized tubes. The progesterone $\left(\mathrm{P}_{4}\right)$ and $\mathrm{E}_{2}$ concentrations were determined using enzyme-linked immu-
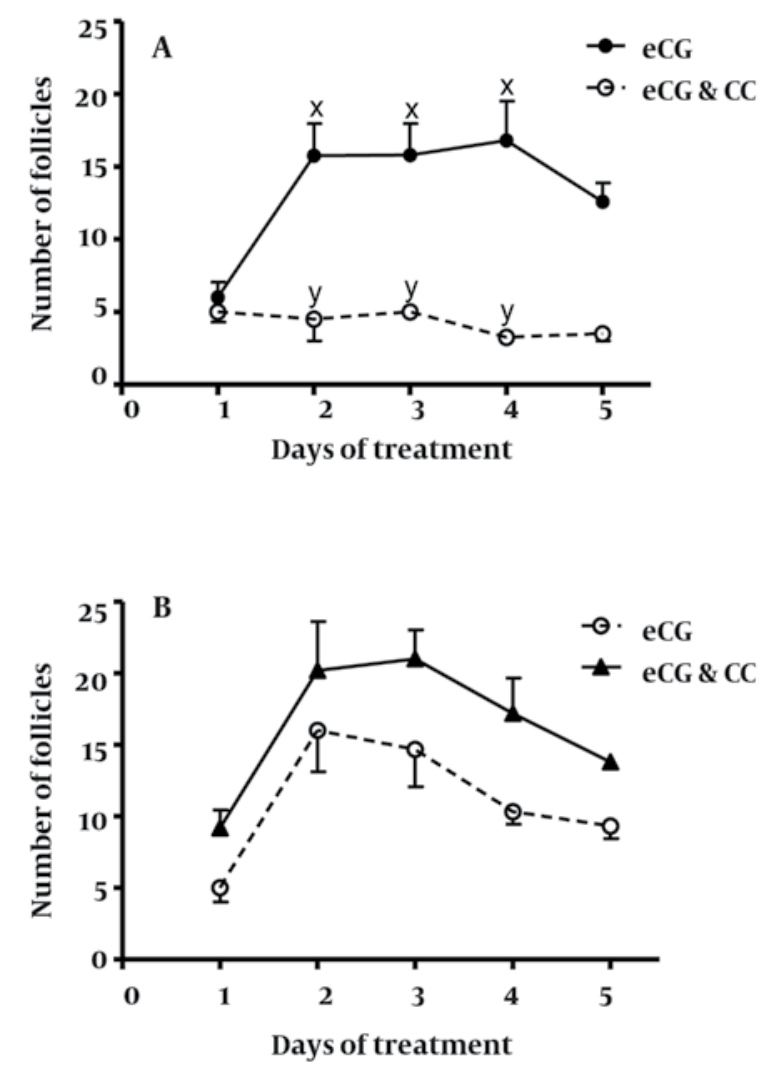

Figure 1. Changes in the Total Number Follicles Between the Groups From Days 1 to 5 (D1-D5).

Values are represented as the Mean \pm Standard Error of the Mean (SEM) of each Time Period. $x, y$ Significant Values $(P<0.05)$ among the Groups of Experiments 1 and 2 . 

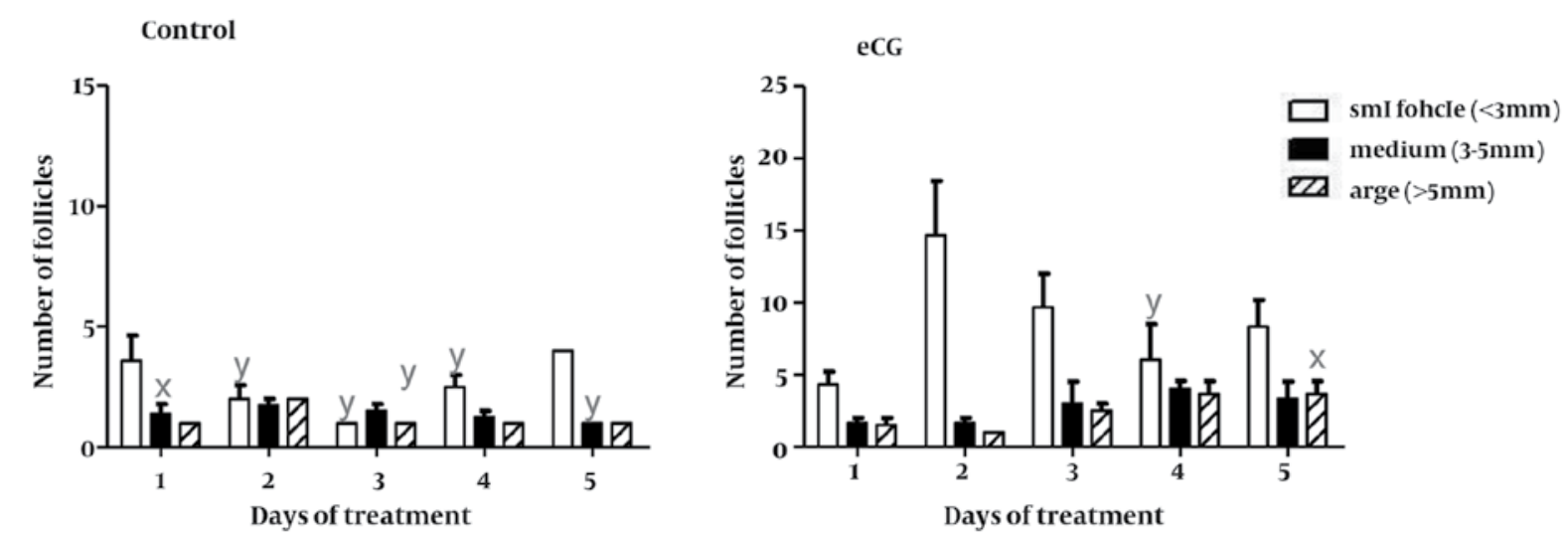

CC
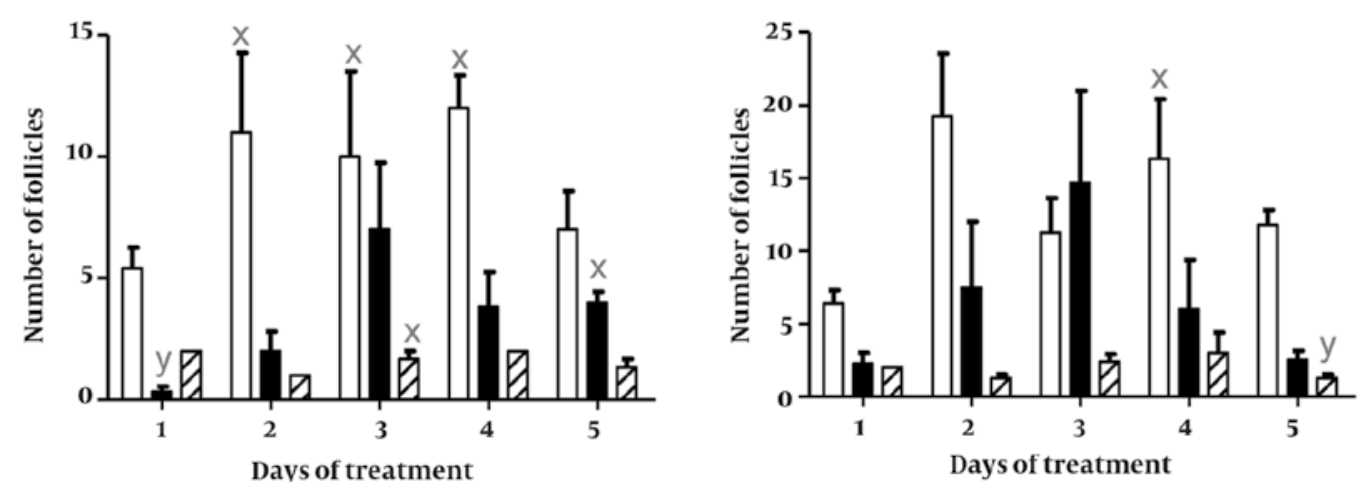

Figure 2. Changes in the Number of Small-Sized Follicles ( $<3 \mathrm{~mm}$ ), Medium-Sized Follicles (3-5 $\mathrm{mm})$, and Large-Sized Follicles $(>5 \mathrm{~mm})$. Follicles from days 1 to 5 (D1-D5) among the Study Groups. Values are represented as the Mean \pm Standard Error of the Mean (SEM) of each Time Period. x,ySignificant Values $(P<0.05)$ among the Groups of Experiments 1 and 2.

nosorbent assay (ELISA) kits (BioCheck Inc., Foster City, $\mathrm{CA}$ ). The ranges of the standards used for the assay were $0.5-50.0 \mathrm{ng} / \mathrm{mL}$ for $\mathrm{P}_{4}$ and $10-1000 \mathrm{pg} / \mathrm{mL}$ for $\mathrm{E}_{2}$. The coefficients of variation for inter-and intrarun precisions were $2.6 \%$ and $4.5 \%$ for the $\mathrm{P}_{4}$ assay and $8 \%$ and $10.3 \%$ for the $\mathrm{E}_{2}$ assay, respectively.

\subsection{Statistical Analysis of the Experimental Data}

Do was defined as the day when natural ovulation was detected. The plasma concentrations of $\mathrm{P}_{4}$ and $\mathrm{E}_{2}$ were analyzed by repeated analysis of variance (ANOVA) to determine the main effects of group, day, and group-by-day interactions. During the analysis of the main effects of group or group-by-day interactions, we also analyzed the intergroup differences in mean values at specific time points by using the Student's $t$ test (JMP statistical software, version 5.1; SAS Institute, Cary, NC, USA). The level of significance was set at $P<0.05$.

\section{Results}

\subsection{Ovarian Response to the Different Treatment}

In Experiment 1, the total number of growing follicles was significantly $(P<0.05)$ higher in the CC group than in the control group (Figure $1 A$ ). In Experiment 2, there was no significant difference between the total number of follicles in the eCG group and eCG and CC group (Fig- ure 1.B).

\subsection{Follicular Dynamics}

The numbers of follicles of different sizes (mean \pm standard error the mean [SEM]) from D1 to D5 are shown in (Figure 2). Compared to the control group in Experiment 1 , the CC group showed a significant increase in the number of small follicles after CC treatment from D2 to D4 and increase in the number of medium-sized follicles at D5. However, CC treatment showed no effect on largesized follicles. In Experiment 2, both the eCG group and the eCG and CC group showed significant increases in the numbers of small- and medium-sized follicles after treatment. Between the groups, the eCG and CC group showed significantly higher numbers of small-sized follicles on D4, and the eCG group showed significantly higher numbers of large-sized follicles on D5.

\subsection{Comparison Between the Hormonal Profiles of the Groups}

In Experiment 1, the $\mathrm{P}_{4}$ concentrations from D1 to D5 showed no effects of group or group-by-day interactions $(P>0.05)$. The $\mathrm{P}_{4}$ concentration was less than $2 \mathrm{ng} / \mathrm{mL}$ from D1 to D3, after which it gradually increased concomitant with the development of new CL (Figure 3A).

In Experiment 2, $\mathrm{P}_{4}$ concentration of the eCG group 

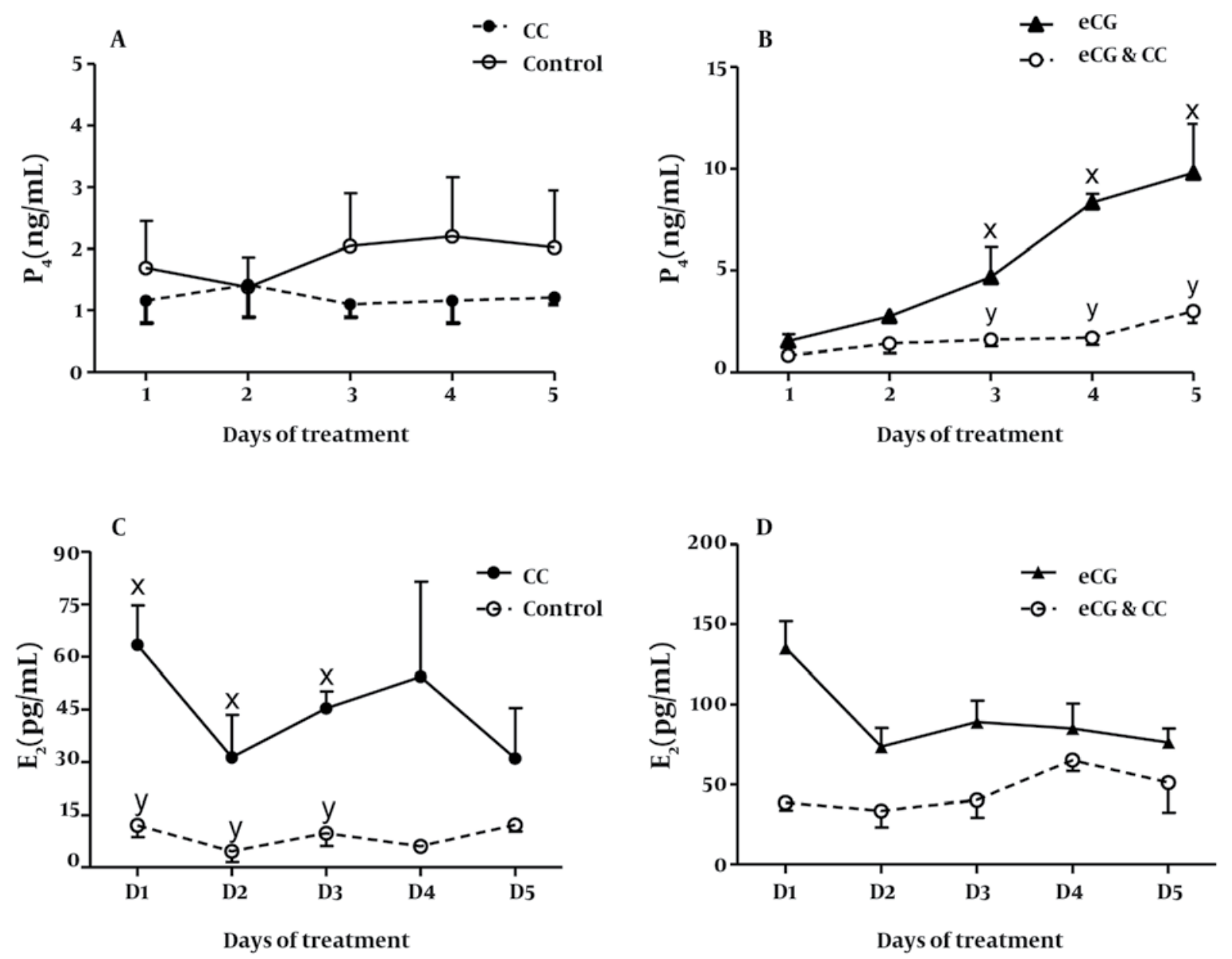

Figure 3. Comparative Changes in the Plasma Concentrations of P4 and E2 in Experiment 1 (A, B) and Experiment 2 (C, D).

Blood Samples were Collected Daily from days 1 to 5 (D1-D5). Values are represented as Mean \pm Standard Error of the Mean (SEM) of each Time Period. $\mathrm{x}$,ySignificant Values $(P<0.05)$ among the Groups of Experiments 1 and 2.

showed a significant increase $(P<0.05)$ from D3 to D5 (Figure 3B). In Experiment 1, the $\mathrm{E}_{2}$ concentration of the $C C$ group was significantly higher than that of the control group from D1 to D3 (Figure 3C). Within the CC group, the $\mathrm{E}_{2}$ concentration gradually increased to reach the maximum level on D3 $(27.8 \pm 10.4)$ and then gradually decreased till it reached $13.3 \pm 4.2$ on D5.

In Experiment 2, group or group-by-day interactions showed no effect on the $\mathrm{E}_{2}$ concentrations analyzed from D1 to D5 (Figure 3D).

\section{Discussion}

The results of our study showed that CC treatment significantly increased the numbers of small- and mediumsized follicles in the CC group animals than in the control animals from D2 to D4, but the treatment had no effect on the number of large-sized follicles. The $\mathrm{E}_{2}$ concentration increased concomitantly with increase in the number of follicles to reach the maximum level on D3. Since final maturation and growth of ovarian follicles require both FSH and luteinizing hormone ( $\mathrm{LH})$, we assume that the effect of LH-induced estrogen was not enough to al- low maturation of the significantly large number of follicles in the CC group ewes. Further, to support this concept, clomiphene and its isomers are estrogenic in some species and antiestrogenic in others; these varying properties have been observed in different organs, tissues, and cell types (9). In intact ewes, clomiphene inhibited ovulation but induced estrous (7), which suggested that different regions of the brain respond differently to clomiphene or its isomers (10). Similar findings were observed in rabbits; CC maintained normal follicular growth and development, but inhibited ovulation in rabbits (6). Further, in women, CC competes with the circulating endogenous $\mathrm{E}_{2}$ for a binding site in the hypothalamus and blocks the negative feedback of estrogen. This effect induces a significant increase in the secretion of GnRH and subsequent secretions of FSH and LH (11). Contrary to this, ovarian activities were inhibited in the ewes, i.e., the follicles failed to develop, ovulations did not occur, and the corpora lutea were not formed (7). No pituitary-stimulatory or gonadotropin-like activity was observed in sheep and rats treated with CC $(5,9)$. We assume that this could be because CC stimulated the secretion of growth hormone (GH), which increased the num- 
ber of small-sized follicles. Generally the relationship between $\mathrm{E}_{2}$ and $\mathrm{GH}$ levels is inversely proportional $(12,13)$. A previous study showed that an $\mathrm{E}_{2}$-induced $\mathrm{LH}$ surge is associated with an obvious GH surge (13). Receiver operating characteristics analysis showed that injection of $E_{2}$ in goats resulted in an increase in GH levels, amplitude, and area under the curve (14). However, in ewes, injection of $\mathrm{E}_{2}$ modulated the activities of $\mathrm{GH}$ releasing hormone (GHRH) and somatostatin neurons through an indirect neuronal pathway (15). A study conducted in cattle showed the relation among $\mathrm{E}_{2}$, GH levels, and the development of small-sized follicles (16). Thus, CC stimulated GH secretion, which increased the number of small-sized follicles and stimulated LH secretion to levels sufficient to convert small-sized follicles to medium-sized follicles, but insufficient to convert the medium-sized follicles to large-sized follicles. Several studies have shown the biphasic control of $\mathrm{E}_{2}$ on $\mathrm{GnRH}$ neurons $(17,18)$. During the late luteal and early follicular phases, low $\mathrm{E}_{2}$ concentration exerts a negative feedback effect on GnRH secretion. In contrast, during the late follicular phase, high E2 concentration results in increased GnRH secretion (19).

In Experiment 1 in the current study, superovulatory responses to different treatments during the first follicular wave were more effective in the CC group than in the control group. Our findings were concurrent with the hypothesis stated in a previous study that superovulatory yields could be increased by initiating the treatment during the early-luteal phase of the estrous cycle (20). One drawback of the current study is the low number of large-sized follicles observed after superovulatory stimuli. However, the ovulatory responses that were detected in our study suggest that ovulation probably took place before the follicles reached their maximum ovulatory size. In a previous study, the ovulatory follicles of superovulated ewes were smaller than those of control ewes. Moreover, the postestrous progesterone profile of all the groups showed a high premature luteal regression rate in the different superovulation groups. Further, premature CL regression could not be identified on ultrasonography at the early stage of the luteal phase (21). Experiment 2 showed that in comparison with eCG treatment alone, the combination treatment of eCG and CC did not induce a significant increase in the number of growing follicles. On the other hand, on D5, a higher number of large-sized follicles was observed in the eCG group than in the eCG and CC group. Ovulation occurred on D3 in the eCG group and $\mathrm{P}_{4}$ levels increased concomitantly, whereas in the eCG and CC group, ovulation was delayed until D5. It seemed that CC, as an antiestrogen, delayed the release of the preovulatory LH surge rather than blocking it and allowed more small- and medium-sized follicles to grow but impaired the final maturation of these follicles and their transformation to large-sized follicles. However, this observation remains a speculation, because LH secretion levels were not measured in our study. In ovariectomized ewes, clomiphene prevented the positive effects of $E_{2}$ concentrations required to induce an LH surge. However, it did not prevent the negative effects of $E_{2}$ on the serum concentrations of LH and by itself acted as a strong agonist resulting in an increased number of GnRH receptors and decreased serum and hypophyseal concentrations of LH (10). Regarding the incompatibility of ovulation in the present study, previous reports have indicated that 2 factors contribute to the variations in the timing of ovulation: firstly, $\mathrm{LH}$ surge and secondly, the median time from the first to the last ovulation (22). $\mathrm{E}_{2}$ concentration of the eCG group was higher than that of the eCG and CC group, suggesting that CC treatment decreased the quality of the growing follicles and interfered with their steroidogenic function. In the same context, in rats, treatment with hCG or prostaglandin F2 $\alpha$ (PGF2 $\alpha$ ) concurrently with CC treatment consistently reversed the antiovulatory effect of CC (23). In rabbits, injection of hCG after CC treatment triggered ovulation (6). According to the present results, it appears that CC is effective in follicular recruitment and their transformation to mediumsized follicles but fails to induce the formation of largesized follicles.

In conclusion, CC treatment per se had a superstimulatory effect on ovulation, thereby increasing the number of recruited follicles in Rahmani ewes rather than affecting the follicular steroidogenic function. Therefore, we recommend that treatments with other drugs, which induce follicle maturation and ovulation, be administered concomitantly with CC.

\section{Acknowledgments}

None declared.

\section{Financial Disclosure}

None declared.

\section{Funding/Support}

None declared.

\section{References}

1. Dickey RP, Holtkamp DE. Development, pharmacology and clinical experience with clomiphene citrate. Hum Reprod Update. 1996;2(6):483-506.

2. Clark JH, Markaverich BM. The agonistic and antagonistic effects of Clomiphene: a review. Pharmacol Theory.1981;15(3):467-519.

3. Nelson LM, Hershlag A, Kurl RS, Hall JL, Stillman RJ. Clomiphene citrate directly impairs endometrial receptivity in the mouse. Fertil Steril Am fertil Soc. 1990;53(4):727-31.

4. Jordan VC. Biochemical pharmacology of antiestrogen action. Pharmacol Rev. 1984;36(4):245-76.

5. Sahu A. Effect of clomiphene citrate on the ovary of a wild rat, Bandicota bengalensis. Acta Anat (Basel). 1987;129(3):248-53.

6. Birkenfeld A, Weber-Benndorf M, Beier HM. Effect of clomiphene citrate on the rabbit ovary. Cell Tissue Res. 1985;239(3):497-503.

7. Lindsay DR, Robinson TJ. The action of clomiphene in the ewe.J Reprod Fertil.1970;23(2):277-83.

8. Tandle MK, Shivaprakash BV, Honnappagol SS, Manjunath MG, 
Appannavar MM. Superovulation using clomiphene citrate in subfertile ewes. Indian veterinary journal.1999;76(4).

9. Pasqualini JR, Sumida C, Giambiagi NA, Nguyen BL. The complexity of anti-estrogen responses. J Steroid Biochem. 1987;27(46):883-9.

10. Gregg DW, Nett TM. Effects of enclomiphene on estradiol-induced changes in LH secretion in ewes. J Anim Sci. 1990;68(10):3293-9.

11. March C. Induction of ovulation. In: Lobo R, Mishell D, Paulson $\mathrm{R}$, editors. Infertility, contraception, and reproductive endocrinology. Oxford, UK: Blackwell Science Ltd; 1992. p. 60.

12. Dutour A, Briard N, Guillaume V, Magnan E, Cataldi M, Sauze N, et al. Another view of GH neuroregulation: lessons from the sheep. EurJEndocrinol.1997;136(6):553-65.

13. Landefeld TD, Suttie JM. Changes in messenger ribonucleic acid concentrations and plasma levels of growth hormone during the ovine estrous cycle and in response to exogenous estradiol. Endocrinology. 1989;125(3):1474-8.

14. Yonezawa T, Mogi K, Li JY, Sako R, Yamanouchi K, Nishihara M Modulation of growth hormone pulsatility by sex steroids in female goats. Endocrinology. 2005;146(6):2736-43.

15. Scanlan N, Dufourny L, Skinner DC. Somatostatin-14 neurons in the ovine hypothalamus: colocalization with estrogen receptor alpha and somatostatin-28(1-12) immunoreactivity, and activation in response to estradiol. Biol Reprod. 2003;69(4):1318-24.

16. El-Sherry TM, Matsui M, Kida K, Miyamoto A, Megahed GA, She- hata $\mathrm{SH}$, et al. Ovarian stimulation with follicle-stimulating hormone under increasing or minimal concentration of progesterone in dairy cows. Theriogenology. 2010;73(4):488-95.

17. Levine JE. New concepts of the neuroendocrine regulation of gonadotropin surges in rats. Biol Reprod.1997;56(2):293-302.

18. Herbison AE. Multimodal influence of estrogen upon gonadotropin-releasing hormone neurons. Endocr Rev. 1998;19(3):30230

19. Goodman R. Neuroendocrine control of the ovine estrus cycle. Knobil E NJe, editor:: Raven Press, New York.; 1994.

20. Gonzalez-Bulnes A, Garcia-Garcia RM, Santiago-Moreno J, LopezSebastian A, Cocero MJ. Effect of follicular status on superovulatory response in ewes is influenced by presence of corpus luteum at first FSH dose. Theriogenology. 2002;58(8):1607-14.

21. Riesenberg S, Meinecke-Tillmann S, Meinecke B. Ultrasonic study of follicular dynamics following superovulation in German Merino ewes. Theriogenology. 2001;55(4):847-65.

22. Bettencourt EM, Dettencourt CM, Chagos de Silva J, Ferreira P, Manito CI, Matos CM, et al. Effect of season and gonadotrophin preparation on superovulatory response and embryo quality in Portuguese Black Merinos. Small Rum Res. 2008;74:134-9.

23. Chatterjee R, Chatterjee A. Blockade of ovulation by clomiphene citrate and its reversal by human chorionic gonadotropin or prostaglandin F2 alpha in rats. Prostaglandins Leukot Med. 1982;9(1):55-60 